\title{
RESPUESTAS JUVENILES AL CAMBIO CLIMÁTICO DESDE LOS CAMPUS DE CLIMÁNTICA
}

\section{YOUTH'S ANSWERS TO CLIMATE CHANGE FROM THE CLIMÁNTICA'S CAMPS}

\author{
http://dx.doi.org/10.15304/ie.29.6341
}

Francisco Sóñora Luna

Director do Proxecto Climántica. GI SEPA-interea

Universidade de Santiago de Compostela

francisco.sonora@usc.es

Aitor Alonso-Méndez

Webmaster de Climántica

Universidade de Santiago de Compostela

aitor@educo2cean.org

Antonio García-Vinuesa

GI SEPA-interea

Universidade de Santiago de Compostela

a.garcia.vinuesa@usc.es

\section{RESUMEN}

En este artículo se analizan los contextos innovadores generados en los campus juveniles del proyecto Climántica y se profundiza en ellos a través de un estudio de caso relativo a la expresión de las valoraciones del alumnado participante en el Primer Campus Climántica Iberoamérica celebrado en San José (Costa Rica) del 8 al 12 de abril de 2019, el cual recibió el máximo patrocinio de la UNESCO. Abarca la evolución del diseño de este tipo de campus que se pusieron en marcha en el curso 20072008 con el objetivo de investigar sobre nuevas formas en las que el alumnado debe aprender para ser líderes creativos y comunicadores eficaces del cambio climático a través de la creación de productos de sensibilización ciudadana. Se recoge también la fundamentación y la evolución del proceso de selección, centrado inicialmente en encuentros presenciales de autores en Galicia, y desde el 2011 a través de una plataforma de presentación de productos multimedia a modo de congreso virtual, hecho que facilitó el proceso de internacionalización.

Palabras clave: estudiantes; educación secundaria; comunicación; UNESCO; interculturalidad; alfabetización climática. 


\begin{abstract}
The present article addresses the innovative contexts which are generated at the Climántica's Youth Camps. A deeper approach is provided through a case study regarding the participants' appreciation of the First Ibero-American Climántica's Youth Camp in San José (Costa Rica), which received the maximum patronage of the UNESCO. The article explains the evolution of the design of this type of Youth Camps, which started in the school year 2007-2008. The target of the Camps is to investigate new ways in which students must learn in order to become creative leaders and effective communicators to make our society aware of climate change throughout the development of awareness raising products. It also includes the evolution of the participants' selection process of the Youth Camp which, initially, focused on face-to-face author meetings in Galicia (Spain). Since 2011 it has been developed through an online platform for multimedia products. This fact has facilitated its internationalization process.
\end{abstract}

Keywords: creativity, teamwork, interculturality, heterogeneous groups, Arts and Science, climate change

\title{
INTRODUCCIÓN
}

Los campus de Climántica surgen en el curso 2007-2008 como una oportunidad de laboratorio pedagógico para encontrar nuevas formas de enseñar y aprender sobre el cambio climático (CC). Para participar en el campus el alumnado debe presentar en un congreso juvenil un trabajo de carácter comunicativo con el objetivo de sensibilizar a la sociedad sobre la crisis climática. El primer congreso juvenil se celebró en el Palacio de Congresos de Santiago en junio de 2008 y en él, de entre los 288 estudiantes que presentaron sus trabajos (Sóñora, 2009), se seleccionó a los autores de los trabajos mejor valorados para participar en el primer campus. El libro de actas de este primer congreso se tituló Ti tamén estás dentro y en él se recogió el trabajo literario íntegro y una breve reseña de cada obra audiovisual. El congreso presencial de 2009 se desarrolló en junio en el Palacio de Congresos de Pontevedra y su libro de actas llevó por título Imos recuperar o mundo. El último congreso presencial se celebró también en el Palacio de Congresos de Pontevedra en junio de 2010 y su libro de actas dejó el lema permanente para este tipo de eventos Xa somos máis recuperando o planeta. En 2011 se sustituyó el formato de congreso presencial por una plataforma de congreso virtual (http://congresovirtual.climantica.org). La aparición de este portal junto con el impacto de la recomendación de Climántica para el uso docente por el Enviado Especial de las Naciones Unidas para el CC, motivaron la celebración en 2012 del Primer Campus Internacional en la localidad de Sada (A Coruña, Galicia). La segunda edición se celebró en Ribadeo (Lugo, Galicia) en agosto de 2013 y la tercera en la Universidade de Vigo (Pontevedra, Galicia) en 2014. Estas dos últimas ediciones se desarrollaron bajo el nombre de Oceántica, siendo patrocinadas por Campus do Mar de la Universidade de Vigo.

El aumento de participación desde otras comunidades autónomas impulsó el cambio de sede hacia el Centro Nacional de Educación Ambiental (CENEAM), donde se celebraron las ediciones de 2015 y 2016. En 2017 se decidió otro cambio de sede al Centro de Divulgación Científica Fábrica Centro de Ciência Viva da Universidade de Aveiro (Portugal), por la adecuación y la accesibilidad a recursos tecnológicos y logísticos que ofrece el centro. Finalmente, en el año 2019 el proyecto 
amplió fronteras desarrollando la primera edición en América Latina, en la localidad de San José de Costa Rica. Esta edición obtuvo el máximo patrocinio de la Organización de las Naciones Unidas para la Educación, la Ciencia y la Cultura (UNESCO) y es objeto de análisis más detallado en el presente trabajo mediante un estudio de caso.

El interés del trabajo que se presenta en este documento radica en la repercusión que tiene la transferencia al contexto latinoamericano de un modelo generado y experimentado en Galicia durante ocho años, en el CENEAM dos años y en Aveiro también 2 años y su consecuente impacto por la obtención del máximo patrocinio de la UNESCO. Se abordan las bases metodológicas y el desarrollo de los procesos previos de selección de los/as participantes, así como la inclusión en el proyecto del seminario docente de investigación acción que busca ofrecer nuevas metodologías de enseñanza-aprendizaje para enfrentar el reto educativo del CC tanto entre el alumnado como entre el profesorado acompañante. Para finalizar se realiza un estudio de caso para valorar la adecuación de la metodología del campus en base a las sugerencias de la literatura científica sobre educación y CC.

\section{EL PROCESO DE SELECCIÓN DE LOS PARTICIPANTES EN LOS CAMPUS}

Para el proceso de selección de los participantes se desarrolló una plataforma online en la que se publican los trabajos del alumnado asesorado por su profesorado. Estos docentes orientadores aspiran a participar en un seminario de investigación-acción que les permita ensayar nuevas formas de enseñar y aprender sobre el CC con la participación y el análisis del desarrollo de un campus de naturaleza científico-artístico-social.

Los productos comunicativos se seleccionan por su potencial capacidad para sensibilizar a la población sobre el CC, incidiendo en la necesidad de su mitigación y adaptación. Pueden presentarse en diversos formatos: relato, poesía, cortometraje, vídeo musical, vídeo de obras de teatro, presentación con fotografías de autoría propia comentadas, cómic, póster, dibujos, etc. Los participantes reciben una formación inicial en el portal del proyecto mediante vídeos explicativos sobre los pasos necesarios para la publicación del trabajo. Igualmente existen tutoriales escritos y un servicio de atención al usuario para facilitar el proceso. Las orientaciones van destinadas tanto al funcionamiento de la plataforma como al uso de los recursos disponibles (libros, vídeos, cursos online, blogs, etc.) para la elaboración de trabajos que pueden realizarse en parejas o individualmente, aunque no se selecciona a más de dos autores de un mismo centro escolar si existen regiones climáticas y/o centros que no tengan representación pero que fueron valorados por el jurado con una puntuación aceptable.

El número de participantes ha ido en aumento desde 30 estudiantes en el primer campus en 2007-2008, hasta los 92 seleccionados en el último celebrado en septiembre de 2019 en Aveiro. Se establecen varios criterios de selección: calidad de los productos; equidad de género; diversidad de representación territorial atendiendo a regiones climáticas bien diferenciadas; y, captación de talentos en función de las competencias asociadas a las creaciones colectivas y de comunicación que se pretenden desarrollar en el campus. 


\section{LOS PRODUCTOS MULTIMEDIA DESARROLLADOS POR LOS GRUPOS DETRABAJO DEL CAMPUS}

En los primeros campus desarrollados en Galicia se investigaron las fórmulas que adoptaban los jóvenes para trasladar a la sociedad mensajes de sensibilización sobre el CC. Desde entonces la tendencia se orientó a la realización de cortometrajes. Los campus de 2009 y de 2010 se desarrollaron en un barco velero de inicios del siglo pasado y durante el recorrido el alumnado analizó la repercusión del clima en las poblaciones y en los recursos de las rías. La travesía finalizó con la presentación pública de las obras en lo que significó el germen de un evento que quedaría establecido como culminación final de los siguientes campus. En el campus del 2011 se integraron las artes plásticas y en el primer campus internacional, en el año 2012, se optó por incorporar también la música, convergiendo ambas artes en la segunda gran producción del campus: el teatro musical. Por tanto, desde el año 2012 la creación colectiva de los campus se centra en dos grandes productos comunicativos: cortometrajes y teatro musical.

Las producciones se desarrollan en equipos heterogéneos que buscan un equilibrio y una complementariedad de edades, de competencias comunicativas y de procedencia geográfica. En la elaboración de cortometrajes se hace uso de equipamiento audiovisual (software de edición, ordenadores y dispositivos de registro de imágenes) así como recursos del ámbito de la robótica, la holografía y la realidad aumentada de la mano de Fábrica centro de Ciencia Viva de Aveiro. El musical integra música, teatro, danza y escenografía utilizando, entre otros recursos, las imágenes y los decorados obtenidos en el taller de artes plásticas.

\section{TEATRO MUSICAL}

En la representación teatral confluyen dos colectivos: de un lado, la banda juvenil; de otro, el grupo de teatro. La banda juvenil está formada por estudiantes con habilidades musicales y que en el proceso de selección declararon interés en formar parte de ella. El grupo de teatro está formado igualmente por los/as alumnos/as que manifestaron interés en participar y formarse en el ámbito de la interpretación teatral. 


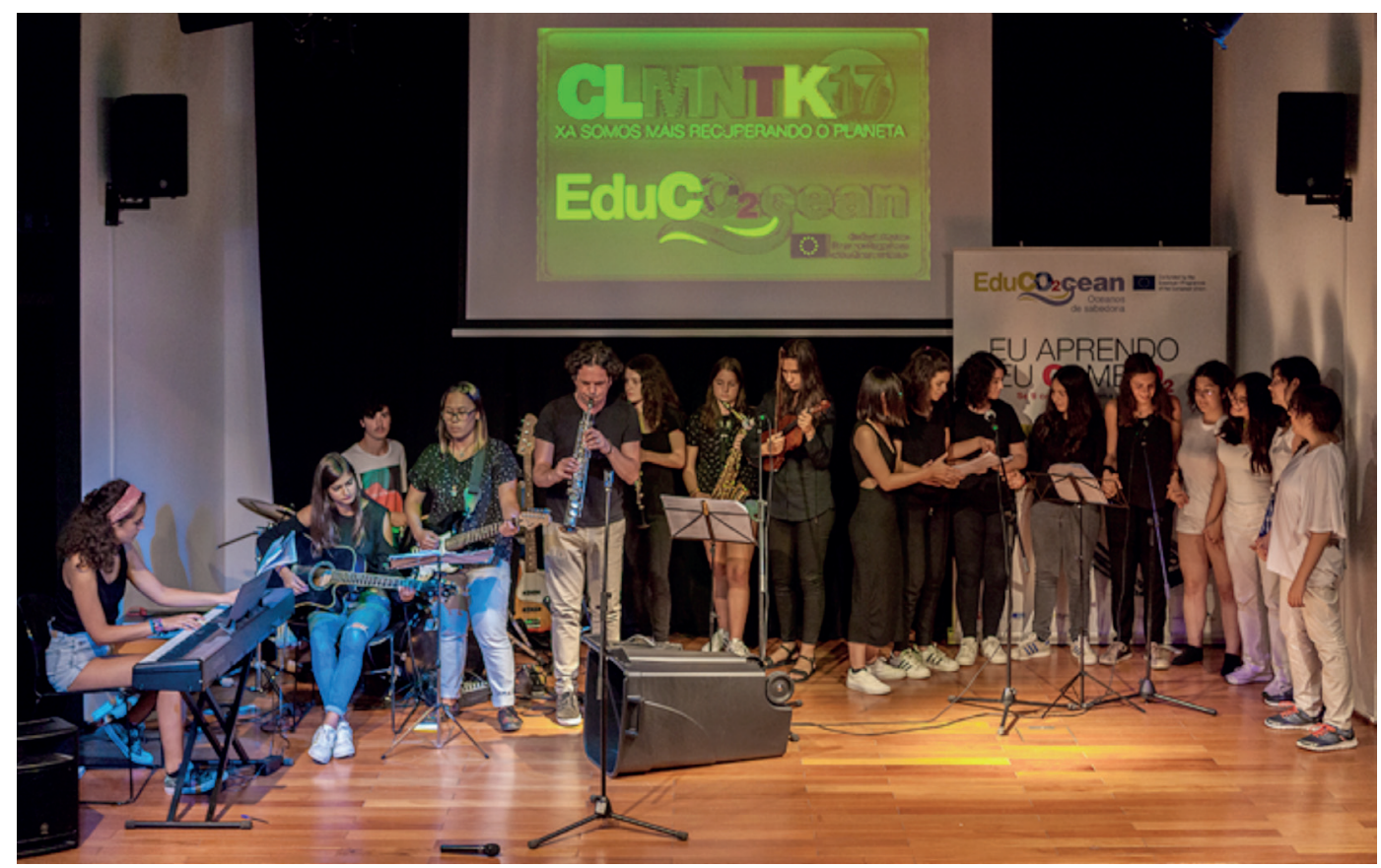

Figura 1. La banda de música y el coro del grupo de teatro durante un ensayo del musical Tragedia en el campus CLMNTK17 (http://red.climantica.org/productos-clmntk19-aveiro/). Fuente: Climántica.

Los/as estudiantes que manifiestan interés en participar como actores y actrices reciben, previamente al inicio del campus, un libreto base creado por los profesores de teatro del proyecto para que elijan por orden de preferencia tres personajes, con la posibilidad de que propongan modificaciones para que se adapten a sus gustos o intereses. También pueden sugerir nuevos personajes, generando en este caso sus diálogos y proponiendo adaptaciones al libreto. Igualmente pueden proponer temas musicales y letras creadas por ellos en coherencia con los diálogos de forma que, con todas estas sugerencias, se reescribe la obra definitiva.

En el teatro musical se integran diversas expresiones artísticas para lanzar un mensaje impactante y eficaz, de modo que incida en la ciudadanía frente a los impactos y las consecuencias del CC en la sociedad y en el medio ambiente. Un ejemplo lo tenemos en la edición 2017 donde se recurrió al género clásico de la tragedia griega con el musical Tragedia. En él se abordaron los problemas derivados de la subida del nivel del mar y sus impactos sobre refugiados climáticos visto desde diferentes continentes y ámbitos climáticos (Figura 2). 


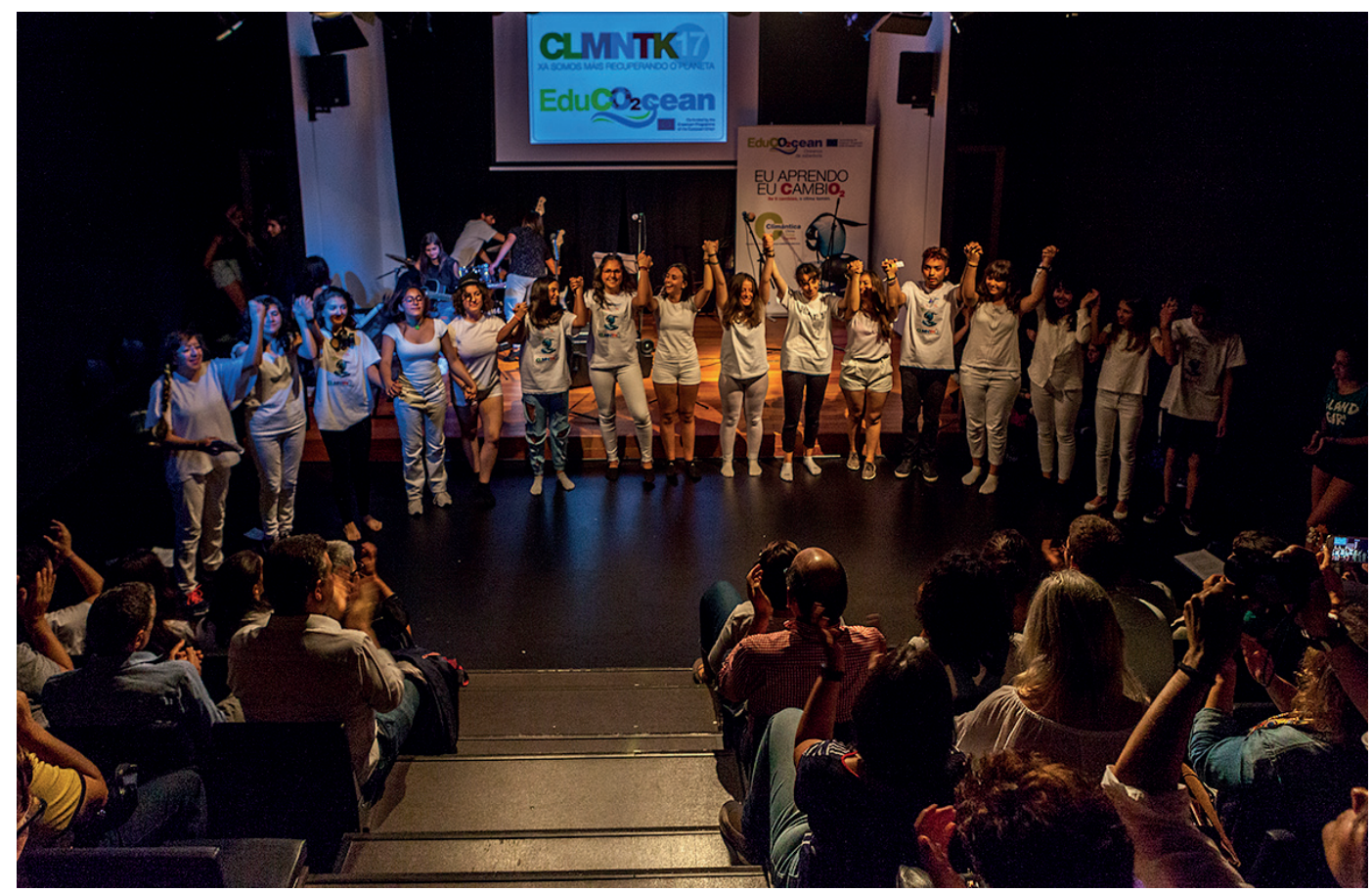

Figura 2. Participantes en el musical Tragedia saludando al final de la representación en la clausura del campus CLMNTK17 http://tv.climantica.org/entradas/492. Fuente: Climántica.

\section{CORTOMETRAJES DE SENSIBILIZACIÓN AMBIENTAL}

Para la realización de los cortometrajes se forman grupos de trabajo con el alumnado que declaró interés en formar parte en estos proyectos. Como indicábamos antes, los equipos son heterogéneos, otorgando a cada participante un rol profesional: guionista, operador de cámara, montador, foto fija, productor, ayudante de dirección, etc. La dirección varía en función de la organización intragrupal, pudiendo ser uno/a o varios los encargados de esta labor y mediados por los educadores del proyecto. Para disponer de material gráfico de las diferentes procedencias, se invita a todo el alumnado a recoger imágenes de sus entornos durante las vacaciones de verano para poder usarlas en los cortometrajes.

Para introducir a los/as estudiantes en los proyectos se inicia su formación con un seminario sobre el tópico Cine, cambio climático y cambio global en el océano en el que reflexionan sobre los diferentes formatos y claves de la comunicación audiovisual para informar y sensibilizar sobre un problema tan complejo como el CC. Esta formación básica sirve de punto de partida para elaborar un argumento sobre el que irán construyendo y concretando los personajes, los escenarios y el guion. En el campus del año 2017 se le sugirió al alumnado crear un cortometraje en relación con la siguiente formulación: realizamos un cortometraje que sensibilice sobre los retos del cambio climático 
y del cambio global en el océano, usando imágenes que obtenemos de nuestras actividades en Aveiro y en los dos museos de divulgación cientifica en los que trabajaremos, con interpretaciones cinematográficas y/o entrevistas, cuando sea oportuno. Con estas imágenes obtenidas a lo largo del campus, junto con las que recogimos durante el verano en los entornos costeros más próximos a los lugares de dónde vivimos los diferentes miembros del grupo, las comparamos en el desarrollo del cortometraje y las ampliamos con realidad aumentada, para finalizar la elaboración del cortometraje con una propuesta de realidad virtual, que utilice como herramientas la robótica y la holografia, para presentar con realidad virtual un futuro sostenible y con respuestas eficaces al cambio climático y al cambio global oceánico.

\section{TALLERES DE FORTALECIMIENTO DE COMPETENCIAS PARA LOS PROYECTOS}

Para reforzar las competencias y habilidades que requieren los proyectos existe un tiempo dedicado a talleres simultáneos (Figura 3). Cada estudiante elige un taller de especialización en los que se integran los componentes de cada proyecto. Hay talleres que sólo refuerzan competencias de interés para los cortometrajes, sin embargo, el contenido de otros converge en ambos proyectos. La oferta formativa se concreta en los siguientes talleres: a) holografía y artes plásticas para realidad virtual y para escenografía del musical; b) robótica para realidad aumentada y virtual; c) simulaciones y demostraciones de Ciencia y Tecnología para proyectos audiovisuales, especialmente desde la dimensión de realidad aumentada; d) fotografía y vídeo; e) edición de vídeo; f) danza; g) teatro; y, h) música.

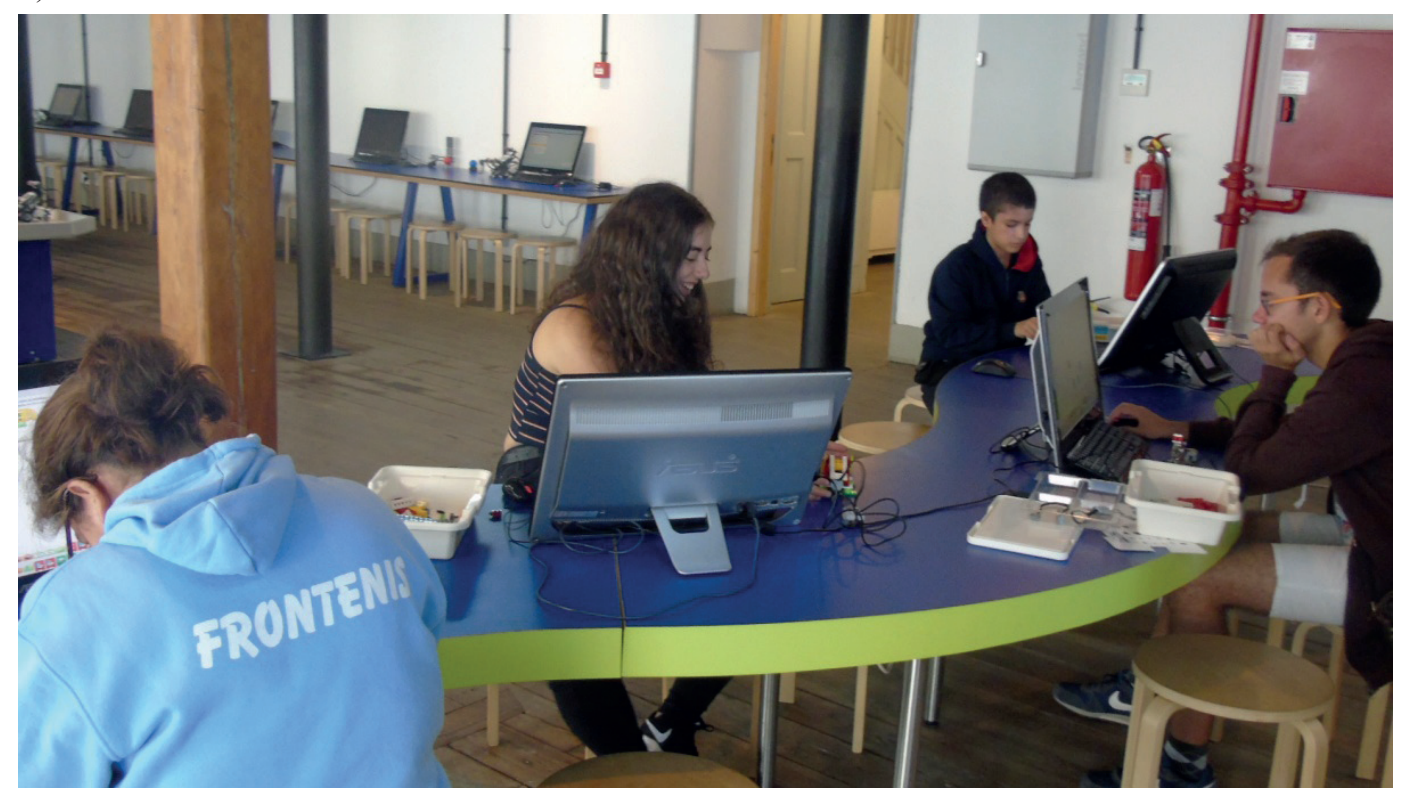

Figura 3. Taller de robótica en el que el alumnado diseña con lego sus prototipos y programación de animaciones para la realidad virtual según el guion. Fuente: Climántica. 


\section{OTRAS ACTIVIDADES DEL CAMPUS: ITINERARIOS, ACTIVIDADES DE OCIO Y DE CONVIVENCIA}

En el campus también se desarrollan actividades en diversos contextos naturales y urbanos dependiendo de los recursos que ofrece el entorno de la sede de celebración del campus. Estas actividades ofrecen una doble dimensión socioeducativa que podemos denominar investigaciónreportaje y lúdico-convivencial-deportiva. Por un lado, se ofrecen contextos para la investigaciónacción donde recoger datos de diversas fuentes para su utilización en la edición de los cortometrajes y la escenografía del musical, por otro, se crean espacios de ocio con el objetivo de afianzar la convivencia grupal (Figura 4). Además, durante las noches se desarrollan actividades lúdicas pensadas para favorecer un ocio valioso, en el que se pueda conciliar la diversión de los integrantes del grupo con su enriquecimiento cultural, la interacción y la cohesión social (Figura 8).

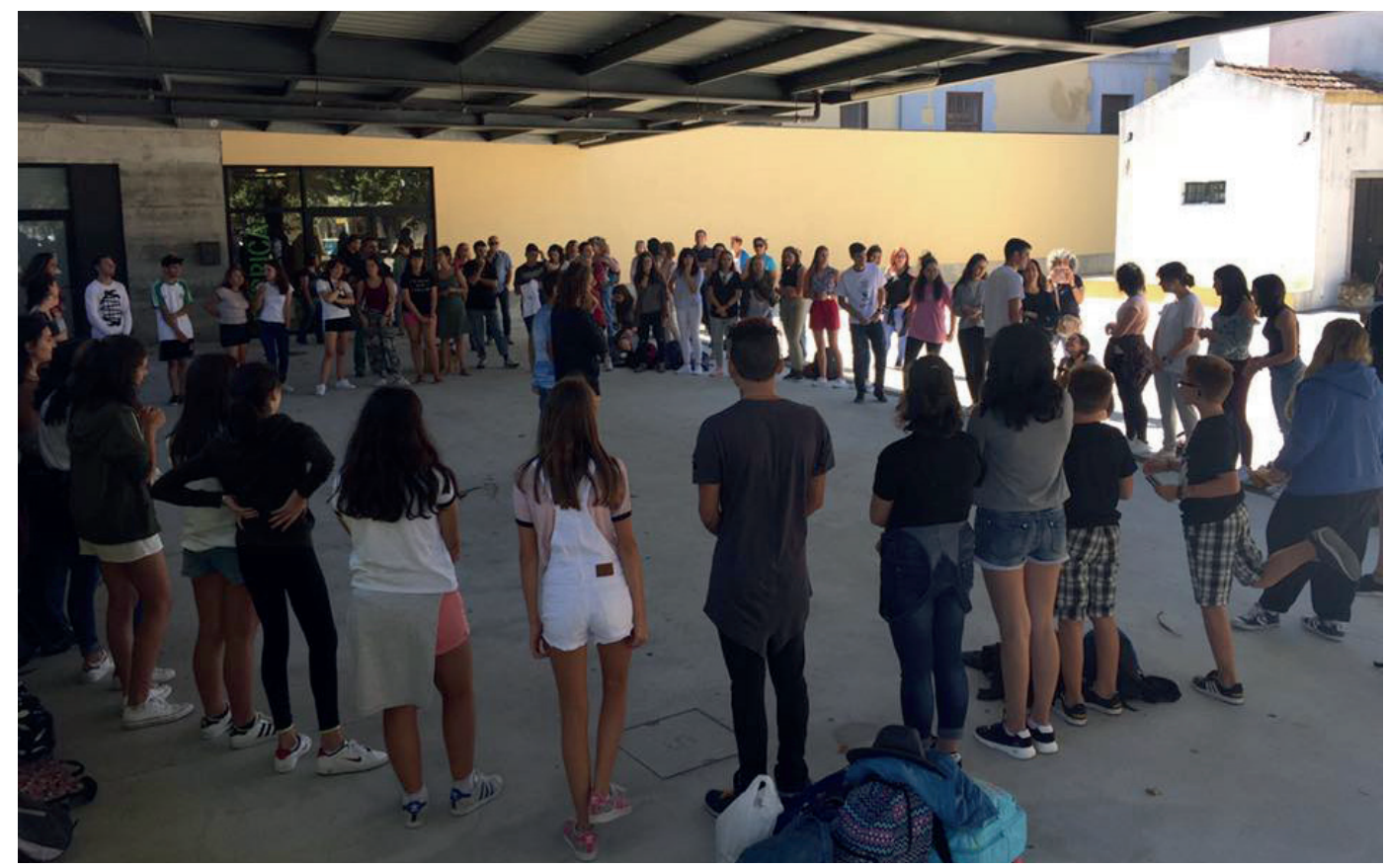

Figura 4. Dinámica de grupo a la llegada del Campus CLMNTK17. Fuente: Climántica.

\section{EL SEMINARIO DOCENTE DE INVESTIGACIÓN-ACCIÓN SOBRE LOS CAMPUS}

Los campus son también espacios de diálogo y transformación que permiten su mejora a través de la participación de docentes de otros países y comunidades autónomas. Fue en 2012 cuando se vio la oportunidad de integrar a estos docentes en el campus, de forma que entendieran su metodología y pudieran aportar nuevas perspectivas enriquecedoras para el evento en particular y el proyecto en general. Por eso desde el primer campus celebrado en 2015 en el CENEAM, los campus llevan 
asociados, como actividades que se realizan en paralelo o de forma complementaria, seminarios docentes de investigación-acción. Son actividades que se acreditan con 50 horas de formación permanente del profesorado por parte del Ministerio de Educación y Formación Profesional del Gobierno de España desde 2015. Estas plazas están asociadas al alumnado seleccionado en el congreso virtual como reconocimiento al docente que orientó su desarrollo y realización.

Estos seminarios tienen por objetivo promover y alentar nuevas formas de enseñar y aprender sobre el CC a partir del análisis y la reflexión del desarrollo del campus. Se pone énfasis en los intereses comunes para llevar a los proyectos educativos adaptaciones de las propuestas experimentadas en el campus, estableciendo las pautas de trabajo mediante una plataforma web colaborativa. Considerando que se incentiva la participación de personas de regiones climáticas diferenciadas, para su organización se estudia la viabilidad de realizar intercambios presenciales con alojamiento en viviendas familiares; una circunstancia que justifica la realización de este evento en los inicios del curso escolar, ya que permite introducir las colaboraciones en las programaciones anuales.

La programación del seminario docente contempla varias actividades, algunas de las cuales, como conferencias y salidas son comunes. En otras actividades coinciden con el alumnado al hacer pequeños grupos rotatorios de observación y análisis del trabajo en proyectos y talleres. De forma paralela a las actividades estudiantiles, los docentes realizan simposios, debates y puestas en común sobre las investigaciones vinculadas al campus, motivo por el cual el seminario docente dispone de un espacio propio para su desarrollo.

Por tanto, estos seminarios docentes no son independientes de las producciones que realiza el alumnado, puesto que hay talleres comunes en los que participan docentes y discentes como el taller sobre el uso del dispositivo móvil para la captura de imágenes. Así mismo, el desarrollo de los trabajos se somete a análisis y debate con el profesorado, por lo que los vídeos y el musical se analizan como herramientas pedagógicas a usar en los propios centros educativos. El aumento de esta sinergia entre el campus y el seminario docente ha sido durante los últimos años una de las mayores demandas del profesorado.

\section{ESTUDIO DE CASO: EL CAMPUS CLMNTK19-UNESCO EN COSTA RICA}

\section{Descripción}

El Campus CLMNTK19-UNESCO (San José, Costa Rica), con una duración de cinco días, basó su desarrollo en el trabajo en equipo de estudiantes de diferentes edades y nacionalidades con el objetivo de crear productos de sensibilización ciudadana ante el CC. De este modo, se situó al estudiante como un puente eficaz entre la ciencia del CC y la sociedad, asumiendo el reto de la divulgación y sensibilización ciudadana sobre el CC en coherencia con los principios de diseño y los objetivos de Climántica (Sóñora, 2011). En este sentido, el $1^{\text {er }}$ Campus Iberoamericano CLMNTK19 obtuvo el máximo patrocinio de la UNESCO al basar las diferentes actividades llevadas a cabo en los Objetivos de Desarrollo Sostenible (ODS) propuestos en la Agenda 2030 de las Naciones 
Unidas (UN General Assembly, 2015), manteniendo como eje central el ODS Nº13 (Acción por el clima). De este modo se trabajó en la relación existente entre la consecución del ODS No13 y sus implicaciones de cara al alcance de los restantes objetivos en base a las sinergias existentes entre todos ellos (IPCC, 2018).
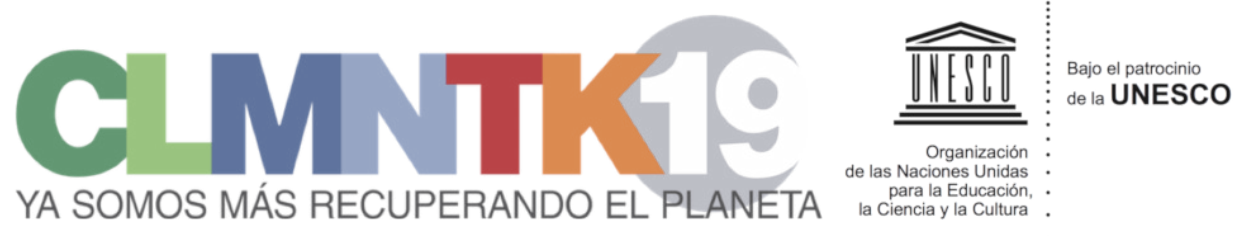

Figura 5. Logo del Campus CLMNTK19 bajo el patrocinio de la UNESCO. Fuente: Climántica.

El evento se inició con una actividad conjunta en la cual docentes y discentes asistieron a dos ponencias en las que se trataron dos pilares básicos a partir de los cuales se desarrollaron las restantes actividades del Campus. La primera de las ponencias, titulada Los 10 conceptos básicos de Climántica para entender el cambio climático abordó los principales aspectos científicos del CC que permiten asumir una visión global sobre sus causas y consecuencias. La segunda de las ponencias, bajo el título de Contando el cambio climático: un mundo de historias bajo los Objetivos de Desarrollo Sostenible abordó diferentes estrategias sobre cómo comunicar el CC a través de la ejemplificación de sus impactos actuales y cómo estos se ven reflejados en diferentes fórmulas de comunicación audiovisual. Tras ello, los participantes comenzaron a trabajar en la producción del musical y los cortometrajes.

El campus se basó en una Educación Ambiental (EA) multidisciplinar y, por lo tanto, en la integración de diferentes disciplinas como la música, las artes plásticas, la danza, el teatro o la ciencia en los productos a realizar. Para ello, los participantes seleccionaron un taller entre la oferta del campus que se concretó en los siguientes: 1) taller de edición de vídeo; 2) taller de ciencia basado en el CC; 3) taller de danza; 4) taller de canto; 5) taller de improvisación teatral; y, 6) taller de artes plásticas, luz y proyección.
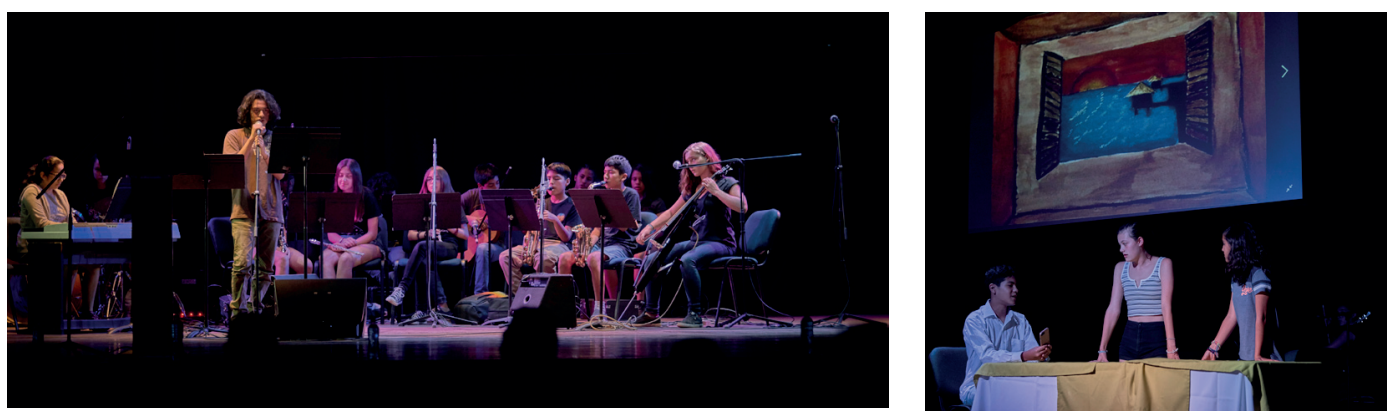

Figura 6. Representación del Musical CLMNTK19-UNESCO (http://red.climantica.org/productos-clmntk19/). Fuente: Climántica. 
Se realizó un teatro musical, tres cortometrajes y un informe semanal de la actividad del campus. En esta ocasión los cortometrajes se realizaron con el propósito de incorporar en su guion la relación del ODS $\mathrm{N}^{\mathrm{o}} 13$ con uno de los ODS restantes que resultase de su interés. En una primera etapa se pusieron en común diferentes ideas a modo de brainstorming en torno a la redacción del guion del cortometraje para que, de este modo, este pudiese reflejar las diferentes visiones y realidades climáticas de los y las integrantes del grupo. A continuación, cada integrante del equipo asumió uno de los roles típicos de una productora de vídeo profesional y, con la mediación del educador del equipo Climántica asignado, desarrollaron su cortometraje. Para la consecución de estos productos en un periodo de tiempo tan corto resultó esencial la existencia de un ambiente adecuado de trabajo y una relación cordial y respetuosa entre los participantes, dejando atrás posibles prejuicios ante diferentes culturas. Para ello, las actividades de convivencia fueron espacios idóneos para la integración de los estudiantes. Ejemplo de ello es el Festival de las Nacionalidades (Figura 9), en el cual cada delegación daba a conocer aspectos relevantes de su cultura como la gastronomía, las tradiciones, la música o los bailes.
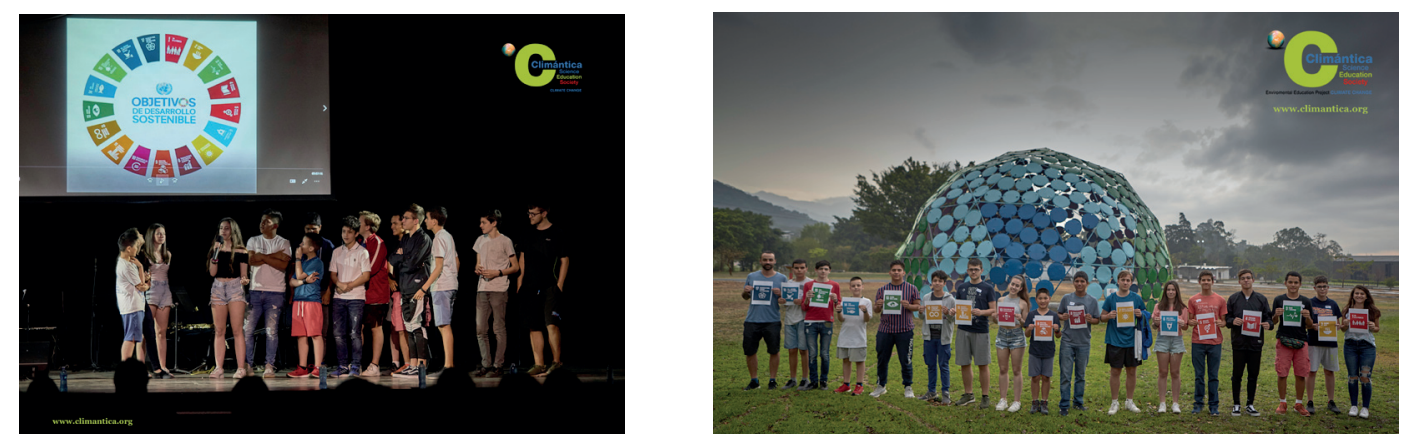

Figura 7. El campus CLMNTK19 basó su desarrollo en torno a los Objetivos de Desarrollo Sostenible de las Naciones Unidas. Fuente: Climántica.

Como anticipamos, de forma paralela se desarrolló el seminario docente de investigaciónacción sobre el Campus CLMNTK19 que siguió la metodología y estructura de los seminarios docentes que se desarrollan desde la edición del 2015. Se abordaron comunicaciones sobre los conceptos clave a comunicar, sobre las fórmulas para crear cortometrajes, se presentó el Proyecto Climántica y se analizaron los productos creados en el campus y su potencial como herramientas pedagógicas. También tuvo una presencia destacada el Colegio Madrid de Ciudad de México, coorganizador de la actividad, analizando su línea de sustentabilidad y de EA, sus prácticas de campo y nuevas propuestas de EA en el marco del proyecto. Sobre el contexto costarricense se analizaron las prácticas escolares de sostenibilidad y el reconocimiento de la bandera azul por parte de Misión 2 Grados, coorganizador local. Desde la Universidad Nacional de Costa Rica se abordó la problemática de los humedales. También participó el Instituto Nacional de Ecología y Cambio Climático de México, que presentó sus materiales didácticos, al igual que la Universidad Nacional Autónoma de México que presentó la situación de la EA en México: estrategias sobre investigación acción. En relación con la investigación didáctica se desarrolló un simposio sobre el análisis del discurso en la educación sobre el CC en Costa Rica, México y España. 
Al igual que la totalidad de eventos realizados en el marco del Proyecto Climántica, el documental que refleja el desarrollo del Campus CLMNTK19, el musical CLMNTK19 y los tres cortometrajes, se encuentran disponibles en la sección ClimánticaTV del portal del proyecto (www. climantica.org).
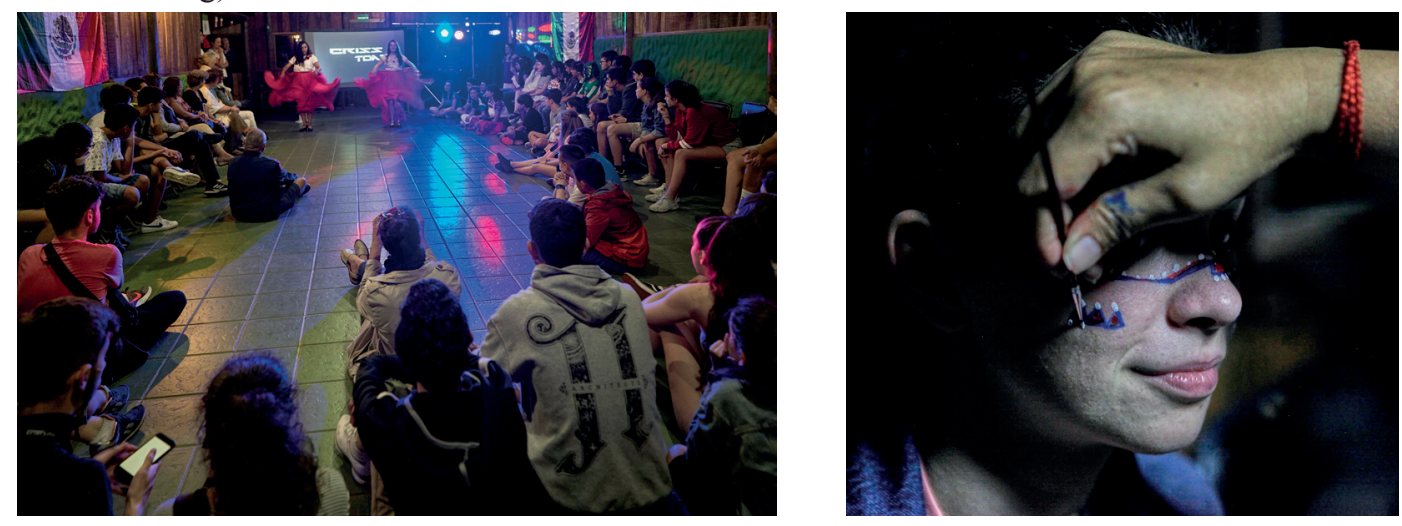

Figura 8. Festival de las nacionalidades del Campus CLMNTK19-UNESCO. Fuente: Climántica.

\section{Contextualización}

El segundo objetivo de este artículo pretende visualizar la utilización de los campus escolares como una actividad educativa con grandes potencialidades pedagógicas y didácticas para la educación del CC en Educación Secundaria, etapa educativa por la que desde hace ya décadas ha transitado una parte de la ciudadanía considerada como generación climática (Feldman, Nisbet, Leiserowitz, y Maibach, 2010), una generación que nació en un momento histórico en el que la certeza del origen antrópico del CC roza el 99\% del consenso científico (Cook et al., 2016). Al respecto de este binomio educación y $\mathrm{CC}$ no podemos obviar el concepto alfabetización climática que viene siendo de gran interés en el ámbito de la investigación educativa con respecto al CC. Sin la intención de entrar en el debate existente sobre la definición de alfabetización climática, Azevedo y Marqués (2017) ofrecen una integración entre lo que señalan son las dos corrientes existentes en torno al concepto: el enfoque educativo y el enfoque comunicativo, sugiriendo un sentido integrado de ambos en el que los conocimientos del campo de la ciencia y la tecnología se retroalimentan con los de las ciencias sociales y la ética para comprender la complejidad y la diversidad de los conflictos existentes en torno al medio ambiente. Tanto estos autores como García-Vinuesa y MeiraCartea (2019) identifican en sus revisiones el documento del U.S. Global Change Research Program (USGCRP) como uno de los más citados y referenciados, por lo que tomaremos esta definición como referencia que, siendo sugerente, no de deja de tener unas altas expectativas sobre el conocimiento científico necesario para alcanzarla. De este modo, una persona climáticamente alfabetizada:

- Entiende los principios esenciales del sistema climático de la Tierra.

- Conoce cómo evaluar información científicamente creíble acerca del clima. 
- Comunica sus conocimientos acerca del clima y el cambio climático de una manera significativa, y

- Es capaz de tomar decisiones informadas y responsables con respecto a acciones que podrían afectar al clima. (USGCRP, 2009, p. 4)

Partiendo de esta definición, otra sugerente lectura para presentar y evaluar el $1^{\text {er }}$ Campus Iberoamericano CLMNTK19 la encontramos en la revisión de Monroe et al. (2017) donde las autoras realizan una revisión sistemática de artículos en los que se describen estrategias educativas sobre CC que ofrezcan instrumentos de medidas y de evaluación para cuantificar los efectos de dichas intervenciones. El resultado es un listado de actividades y una serie de sugerencias sobre estrategias efectivas para la educación del CC, todas ellas encuadradas en la Educación Primaria, Secundaria y Superior. Las autoras establecen dos líneas principales que incrementan las posibilidades de éxito de los proyectos educativos sobre CC:

“(1) Programas centrados en hacer la información climática personalmente relevante y significativa para los discentes.

(2) Las actividades y las intervenciones educativas diseñadas para comprometer a los discentes.” (Monroe et al., 2017, 9)

A pesar de estas sugerencias, el "objeto" CC presenta algunas dificultades en la consecución de esta significatividad y compromiso necesarios para un cambio pro-climático desde el punto de vista actitudinal y comportamental. En este sentido Salomon, Preston y Tannenbaum, (2017) sugieren que la indefensión climática juega un papel fundamental en el cambio de conductas y hábitos pro-climáticos o pro-ambientales. La complejidad del problema y la diferencia espaciotemporal de las causas y las consecuencias favorecen esta indefensión climática, en un símil de la indefensión aprendida clásica de Seligman, que sostiene que ante una amenaza o estímulo negativo frente al cual no podemos hacer nada, o sentimos que no podemos, el resultado comportamental es la inacción o inhibición de cualquier acción de respuesta. Las autoras sugieren que por un lado los tiempos del CC, lentos para la percepción humana pero extremos para el sistema climático, no permiten reforzar las acciones pro-climáticas ya que sus resultados no son perceptibles a corto y medio plazo. Por otro lado, el hecho de que "sigue viéndose como un riesgo moderado y lejano que impactará a otros antes que a mí" (González-Gaudiano, 2012, p. 1056) y que los medios de comunicación han contribuido al poner el foco informativo en las consecuencias en forma de catástrofes naturales (González-Gaudiano, 2007) en vez de centrarse en las causas, dificulta vincular directamente acciones cotidianas y consecuencias. Las autoras reclaman así la necesidad de una educación para el CC fundamentada en valores productores de vínculos emocionales entre nuestros actos, característicos de los estilos de vida de las sociedades más desarrolladas y opulentas, y las consecuencias que sufren en mayor medida las sociedades menos desarrolladas y más empobrecidas. Es aquí, a diferencia de la indefensión aprendida clásica, donde la motivación y la ética juegan un papel fundamental para fomentar la eficacia climática (Salomon, Preston, y Tannenbaum, 2017) que ofrezca sentido y compromiso a las acciones necesarias para la transición ecológica y el cambio. Es en este sentido donde los campamentos se presentan como un recurso educativo con grandes potencialidades pedagógicas para la enseñanza/aprendizaje del CC. En este sentido, Ramsing 
y Sibthorp (2008) indican como, en campamentos de verano, la combinación de competencias personales y de motivación favorecen el compromiso activo en la producción y promoción de comportamientos sociales que por lo general suelen generar menos interés en los adolescentes. Del mismo modo, Skanavis y Kounani (2018) subrayan la eficacia de los campamentos en la generación y promoción de la afectividad y de las emociones entre participantes con la consecuente creación de fuertes vínculos entre los y las participantes, vínculos afectivos necesarios para promover la eficacia climática como objetivo educativo en la lucha frente al CC.

\section{Metodología}

Con el objetivo de analizar $1^{\text {er }}$ Campus Iberoamericano CLMNTK19, se ha empleado una metodología mixta aplicando el método asociativo/proyectivo: libre asociación o asociación libre.

A través del empleo del método de libre asociación se pretende comprender la representación colectiva e individual que los/as participantes tienen del Campus. Se seleccionó este método asociativo ya que "el carácter espontáneo [...] y la dimensión proyectiva de esa producción [datos obtenidos] deberían permitir así tener acceso, mucho más rápido que en una entrevista" (Abric, 1994, 59) y porque es rápido de implementar, por lo que se adaptaba al carácter y los tiempos del campus donde era muy difícil acceder a todos/as los/as participantes a la vez.

\section{Participantes}

En el $1^{\text {er }}$ Campus Iberoamericano CLMNTK19 participaron 78 estudiantes de entre 11 y 18 años, 23 profesores de Secundaria, 2 profesores de Primaria, 7 educadores y un técnico audiovisual. El alumnado y el profesorado procedían de 4 países diferentes: España (34/10), México (20/10), Costa Rica (11/1) y Perú (13/2).

\section{Aplicación de instrumento y análisis de datos}

La aplicación del método de libre asociación se llevó a cabo durante la realización de los talleres, por lo que no se pudo acceder a todos los participantes, ya que estaban divididos en los diferentes talleres por todo el recinto del Parque de la Libertad (Costa Rica). Participaron 58 estudiantes: 28 de España, 14 de México, 9 de Costa Rica y 7 de Perú.

Se empleó la técnica de libre asociación de respuesta simple (Dany, Urdapilleta, y Monaco, 2015) en la cual sólo se emplea un término de inducción sin ninguna restricción de carácter semántico o gramatical en la respuesta. Se repartió un papel a cada participante con números del 1 al 5 distribuidos verticalmente indicándoles que debían escribir una palabra en cada uno de los números en el orden en el que les vinieran a la cabeza con respecto a un tema determinado que se le diría cuando no existieran dudas. Se resolvieron las dudas y se indicó que el tema era "el Campus CLMNTK". La cumplimentación se realizó en tres fases durante un total de 15 minutos: 
- Fase 1. Registro de las cinco palabras para calcular el rango de frecuencia y el rango de aparición. El rango de frecuencia permite acercarse a la representación colectiva mientras que el análisis del rango de aparición facilita una aproximación a una realidad más individual.

— Fase 2. Significación personal. Se les indicó que reflexionando sobre las palabras escritas las ordenaran según la importancia que les concedían, con esto se pretendía profundizar en la importancia personal que concedían a cada concepto.

- Fase 3. Contextualización semántica. Para finalizar se les indicó que sintetizaran en una frase por qué habían seleccionado la primera palabra como la más importante con el objetivo de minimizar sesgos de interpretación.

\section{Resultados}

\section{Libre asociación de respuesta simple}

Fase 1. Rango de frecuencia / rango de aparición

En la tabla 1 se ofrecen las frecuencias de aparición de las 323 palabras más repetidas mientras que la tabla 2 muestra las frecuencias de las palabras que los/as participantes escribieron en primer lugar inmediatamente después de indicar verbalmente el concepto inductivo "Campus Climántica" durante la fase 1 de aplicación del método.

Tabla 1. Frecuencia de aparición de palabras registradas por los/as participantes al finalizar la fase 1 de aplicación del método libre asociación de respuesta simple. Las palabras con frecuencia 1 y 2 no se registran en la tabla. Fuente: elaboración propia

\begin{tabular}{lcll}
\hline \multicolumn{1}{c}{ Palabras } & F & Palabras & F \\
\hline $\begin{array}{l}\text { Amigos } \\
\text { Divertido }\end{array}$ & 12 & $\begin{array}{l}\text { proyecto, aprender, } \\
\text { aprendizaje, compañerismo }\end{array}$ & 5 \\
Arroz & 10 & $\begin{array}{l}\text { Interesante, autobús, trabajo } \\
\text { cultura, amistad, unión, video } \\
\text { talleres, equipo, conocer, }\end{array}$ & 6 \\
Comida, diversión & 8 & & \\
Clima & 7 & $\begin{array}{l}\text { emocionante, fiesta, campus, cansado, cambio-climático, medio- } \\
\text { ambiente, plantas, WIFI }\end{array}$ & 3 \\
Música, naturaleza & 6 & & \\
\hline
\end{tabular}


Tabla 2. Frecuencia de aparición. Palabras escritas en primer lugar después de indicar el término inductivo "Campus Climática". Fuente: elaboración propia.

\begin{tabular}{lll}
\hline Palabras & F & Palabras \\
\hline Divertido & 7 & $\begin{array}{l}\text { Actividades, activo, amor, arroz, ayudar, bueno, calentamiento global, cambio, 1 } \\
\text { cambio climático, campus, chulo, climántica, comida, compañerismo, compartir, } \\
\text { conocer gente, conocimiento, crisis, cultura, divertido, divertido, emocionante, } \\
\text { felicidad, hablar, importante, naturaleza, oportunidad, positivo, proyecto, sueño, } \\
\text { unión, vida, zulo }\end{array}$ \\
$\begin{array}{l}\text { Amigos, diversión } \\
\text { clima, genial, vídeos } \\
\text { medio ambiente, }\end{array}$ & 2 & \\
\hline
\end{tabular}

\section{Fase 2. Significación personal}

La tabla 3 muestra las frecuencias de las palabras seleccionadas por los/as participantes como más importantes de entre las 5 que escribieron en la fase 1.

Tabla 3. Frecuencia de las palabras seleccionadas como más importantes (fase 2) de entre las 5 registradas en la fase 1. Fuente: elaboración propia.

\begin{tabular}{lll}
\hline Palabras & F & Palabras \\
\hline $\begin{array}{l}\text { amigos, cambio, medio } \\
\text { ambiente, }\end{array}$ & 3 & $\begin{array}{l}\text { actividad, amabilidad, amigable, amor, aprender, árbol, arroz, bueno, campo, } \\
\text { comida, compromiso, comunicación, conocedor, conocer, convivencia, crisis, } \\
\text { cultura, especial, guitarra, importante, internacional, juventud, libertad, lucha, } \\
\text { naturaleza, nuevos amigos, personas chivas, planeta, reflexión, socialización, } \\
\text { unión, viejos conocidos, yo }\end{array}$ \\
$\begin{array}{l}\text { cambio climático, } \\
\text { clima, climántica, } \\
\text { compañerismo, } \\
\text { diversión, divertido, } \\
\text { equipo, genial }\end{array}$ & 2 & \\
\hline
\end{tabular}

Fase 3. Contextualización semántica

En la fase 3 se les solicitó a los/as participantes que sintetizaran en una frase por qué habían seleccionado una de las cinco palabras como más significativa. Con esta descripción y por agrupamiento por cercanía semántica se obtuvieron los conceptos de agrupación que se muestran en la figura 9. En la tabla 4 se ofrecen algunas de las síntesis de los/as participantes asociadas a la palabra que seleccionaron.

Tabla 4. Ejemplos de las palabras seleccionadas como más importantes y la explicación ofrecida del porqué de la selección. La técnica de contextualización semántica permitió evitar sesgos de interpretación y organizar los términos de agrupación. Fuente: elaboración propia.

\begin{tabular}{llll}
\hline Palabra & Contextualización semántica & Concepto(s) de agrupación & País \\
\hline Comunicación & Porque es un medio de socialización con otras culturas & AMISTAD y CULTURA & CR \\
Amigos & $\begin{array}{l}\text { Me parece más importante hacer amigos porque puedo } \\
\text { aprender de otras culturas y pasarlo mejor todos juntos }\end{array}$ & AMISTAD y CULTURA & ES
\end{tabular}




\begin{tabular}{|c|c|c|c|}
\hline Internacional & $\begin{array}{l}\text { Porque ayuda a hacer vínculos con personas de distintos } \\
\text { países }\end{array}$ & AMISTAD y CULTURA & ES \\
\hline Juventud & $\begin{array}{l}\text { Los ordené pensando en todos los pasos para lograr el } \\
\text { cambio, sin juventud no hay gente, sin amor no hay } \\
\text { comunidad, sin comunidad no hay unión y sin unión no hay } \\
\text { cambio }\end{array}$ & $\begin{array}{l}\text { JÓVENES, AMOR y } \\
\text { CAMBIO }\end{array}$ & $\mathrm{ME}$ \\
\hline Especial & $\begin{array}{l}\text { Porque trata un tema donde a los niños muchas veces no se } \\
\text { nos tiene en cuenta }\end{array}$ & JÓVENES & ES \\
\hline Amor & $\begin{array}{l}\text { Cualquier objetivo se tiene que cumplir con un amor genuino } \\
\text { al cambio, al mundo, a compartir y creo que si existe la } \\
\text { ausencia de este e objetivo se puede perder }\end{array}$ & AMOR y CAMBIO & ME \\
\hline Compromiso & $\begin{array}{l}\text { Si no hay compromiso en lo que haces no hay amor. Si } \\
\text { queremos cambiar el mundo lo tenemos que cambiar con el } \\
\text { amor }\end{array}$ & AMOR y CAMBIO & $\mathrm{ME}$ \\
\hline Reflexión & La reflexión es el cambio & REFLEXIÓN y CAMBIO & $\mathrm{ME}$ \\
\hline Diversión & $\begin{array}{l}\text { Porque el campamento tiene como finalidad divertirse y } \\
\text { aprender }\end{array}$ & DIVERSIÓN y APRENDER & ES \\
\hline Naturaleza & $\begin{array}{l}\text { Naturaleza porque es el medio donde vivimos y el único que } \\
\text { tenemos. Además es tan bello que da lástima perderlo }\end{array}$ & MEDIO AMBIENTE & $\mathrm{CR}$ \\
\hline $\begin{array}{l}\text { Cambio } \\
\text { climático }\end{array}$ & Porque el cambio climático deja a muchas personas sin hogar & CAMBIO CLIMÁTICO & ES \\
\hline Conocedor & $\begin{array}{l}\text { Porque me gustó mucho conocer otras culturas de diferentes } \\
\text { países, como es su acento, etc... Además porque fue bueno } \\
\text { conocer más a fondo Climantica19 }\end{array}$ & CULTURA y CLMNTK & $\mathrm{PE}$ \\
\hline $\begin{array}{l}\text { Medio } \\
\text { ambiente }\end{array}$ & $\begin{array}{l}\text { Medio ambiente es el motivo por el que estamos aquí, para } \\
\text { luchar juntos por protegerlo }\end{array}$ & MEDIO AMBIENTE & ES \\
\hline Actividad & $\begin{array}{l}\text { Porque si todos trabajan en equipo se puede lograr } \\
\text { muchísimo }\end{array}$ & EQUIPO & $\mathrm{ME}$ \\
\hline Crisis & $\begin{array}{l}\text { Porque estamos ante una crisis que puede cambiar nuestra } \\
\text { forma de vivir y no estamos haciendo nada }\end{array}$ & CAMBIO CLIMÁTICO & ES \\
\hline Divertido & $\begin{array}{l}\text { Es necesario hacer las cosas porque nos gustan no porque } \\
\text { alguien nos obligue, lo más importante para mí es divertirme }\end{array}$ & DIVERSIÓN & $\mathrm{CR}$ \\
\hline
\end{tabular}

ES: España; ME; México; CR: Costa Rica; PE: Perú.

En el diagrama de la figura 9 obtenemos dos conceptos principales, Amistad y Cambio, que están vinculados a través del concepto Equipo. Cada uno de estos conceptos principales están vinculados con otros conceptos periféricos que definen y aclaran sus significados. En el caso del concepto principal Amistad aparecen otros tres conceptos significativo Diversión, Cultura y Medio Ambiente, que se vinculan con el primero a través del concepto Aprender. Entre estos conceptos centrales y periféricos vinculados entre si aparecen otros conceptos circundantes como: Música, Proyecto, Alegría, Lucha y Libertad. 


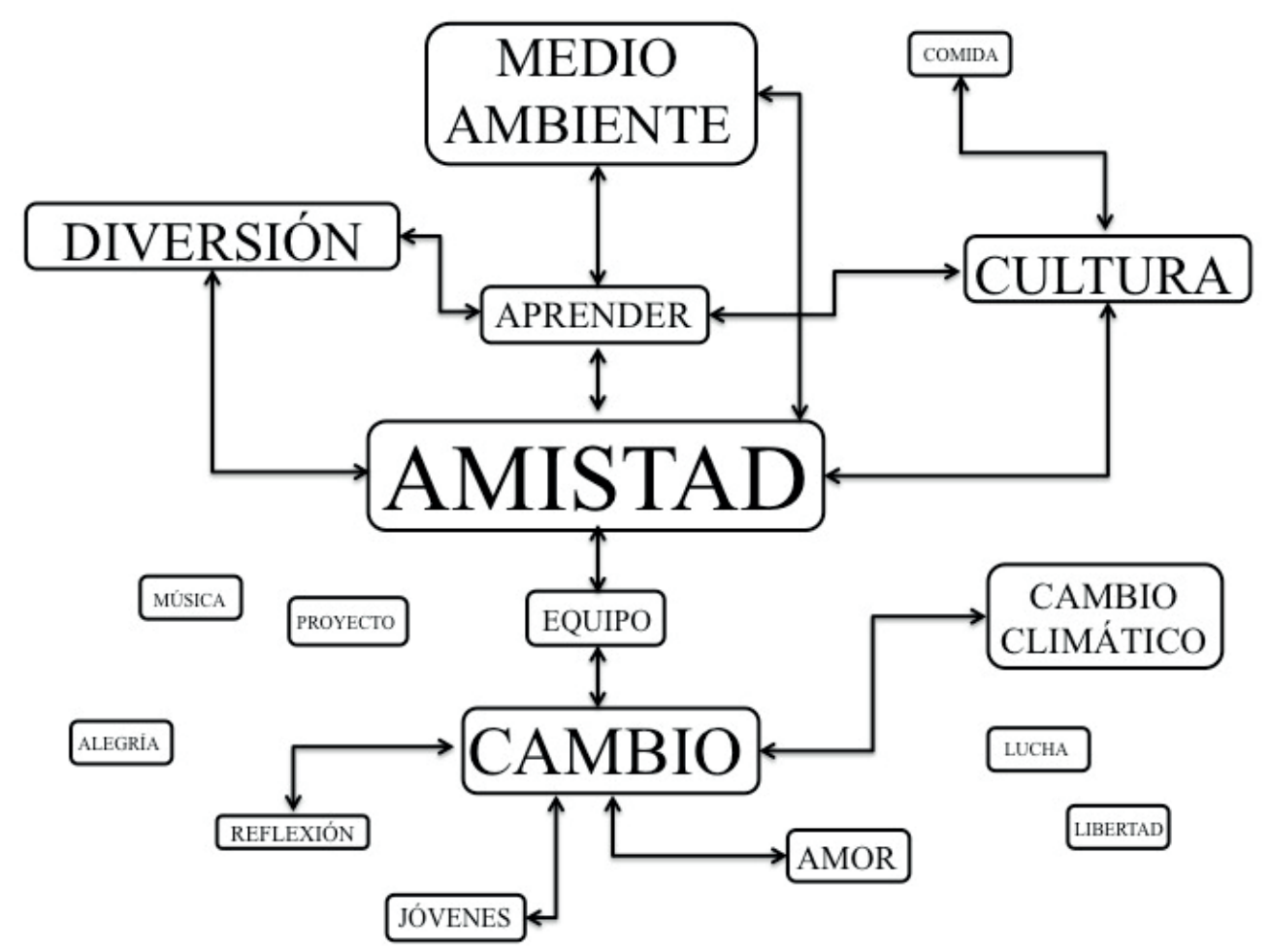

Figura 9. Diagrama de las conexiones y los conceptos de agrupación considerados más importantes por los/as participantes al escuchar el concepto inductivo "Campus Climántica". El tamaño de la fuente indica la mayor o menor frecuencia del concepto. Se desestimó la palabra Climántica con una frecuencia igual a 4, porque era el propio término inductivo utilizado en la asociación libre. Fuente: elaboración propia.

\section{Discusión}

\section{Las emociones y el aprendizaje como motor de cambio}

Los resultados obtenidos de aplicar el método de asociación libre apuntan a que el $1{ }^{\mathrm{er}}$ Campus Iberoamericano Climática persigue las recomendaciones pedagógicas sugeridas por los estudios citados. Salomon, Preston y Tannenbaum (2017) sugerían que para promover la eficacia climática frente a la indefensión climática era necesario crear vínculos emocionales que permitieran conectar las causas, producto de nuestra vida cotidiana, y las consecuencias, más visibles en lugares lejanos (González-Gaudiano, 2012) dotando de significatividad a las acciones de lucha frente al CC. La técnica de asociación libre permite comprobar como esta dimensión afectiva es el elemento principal de la representación de los/as participantes en el Campus (Skanavis y Kounani, 2018) representada por el concepto Amistad vinculada directamente con otros elementos periféricos como el de Cultura (Figura 9). Este vínculo afectivo entre sociedades y culturas diferentes tuvo su expresión más rotunda tras el terremoto en México de 2017 — no confunda el lector aquí, las manifestaciones de 
los movimientos tectónicos con el CC, una de esas concepciones alternativas tan extendidas (Espejel y Flores, 2015) — donde toda la "Comunidad Climántica" de España se volcó con vídeos y frases de apoyo en las redes sociales hacia sus compañeros/as mexicanos/as.

Las autoras también indican como la motivación juega un papel fundamental en el desarrollo de la eficacia climática. En este caso podemos comprobar una dimensión motivacional en la representación que describe la figura 9, donde el segundo elemento más importante de la representación lo encontramos en el concepto Cambio que se retroalimenta con Amor y que se vincula con Amistad a través del concepto Equipo. Una motivación que no es entendida únicamente como vehículo del sentido de eficacia — climática — sino como motor de aprendizaje — Aprenderen un contexto intercultural - Cultura - de Diversión y de Amistad para aprender sobre el Medio Ambiente y plantear acciones de Cambio frente al Cambio Climático.

Esta dimensión motivacional se expresa igualmente en todas las ediciones de los campus realizados dentro del proyecto Climántica, ya que para participar el alumnado interesado debe crear una producción comunicativa sobre CC en forma de creación audiovisual, poema, relato, ilustración, canción, etc. El historial de la web oficial del proyecto es una clara muestra de la numerosa participación, así como la propia visualización de los contenidos a nivel internacional que se manifiesta en un portal que supera ampliamente el millón de usuarios únicos y que se aproxima a dos millones de visitas. Este formato de participación, junto con la realización de los diversos proyectos de comunicación durante el campus, coincide de forma clara con el tercer principio esencial del USGCRP (2009).

Con respecto al compromiso que genera la eficacia climática que indicaban Salomon, Preston, y Tannenbaum (2017), es una actitud difícil de evaluar ya que precisaría de un seguimiento en el día a día del alumnado que participó en el Campus, sin embargo, este compromiso lo podemos comprobar en diferentes muestras vinculadas a otros campus realizados en el proyecto:

- La coordinación y la organización de la delegación de Santiago de Compostela del movimiento Friday For Future, está formada por participantes de anteriores campus.

- La creación de un manifiesto a nivel mundial a partir del trabajo colaborativo llevado a cabo por los integrantes de Red Climántica, basado en el libreto del Musical representado en el Campus CLMNTK19 de Aveiro La Vuelta al Clima en 10 escenas. Se trata de un producto audiovisual llevado a cabo por 27 comunidades educativas de 10 países diferentes disponible en http://red.climantica.org/arranca-red-climantica-de-la-investigacion-a-lasensibilizacion/.

- El equipo de educadores del campus, formado por 7 educadores, participaró previamente como alumnado del campus.

Un compromiso reforzado y promovido, como indicaban Ramsing y Sibthorp (2008), por contextos educativos en los que la motivación y las competencias se integran. Competencias que el campus promueve con la realización de los diversos talleres y proyectos en equipo, siendo las actividades que más tiempo acaparan en el trabajo educativo del campus, como así se identifica en la representación ofrecida en la figura 9. 
Con todo esto los resultados sugieren que el $1^{\text {er }}$ campus Iberoamericano CLMNTK19 cumple con las dos principales líneas que proponían Monroe et al. (2017) para asegurar el éxito de intervenciones o proyectos educativos sobre el CC, dotando de relevancia y significatividad a la información sobre CC y ofreciendo actividades que buscan y promueven el compromiso de los/as participantes.

\section{Conclusiones}

Según lo expuesto podemos considerar que el $1^{\text {er }}$ Campus CLMNTK19 desarrollado dentro del Proyecto Climántica de EA para el CC, cumple con las líneas sugeridas por la literatura científica. De su alcance se puede destacar:

— Está siendo cada vez más internacional implicando ya a tres continentes.

- Los participantes se empoderan como mentores activos del proyecto en su centro y llegan incluso a liderar procesos de comunicación del $\mathrm{CC}$ a la sociedad en espacios públicos y procesos de investigación sobre los impactos del CC en el entorno (Sóñora y AlonsoMéndez, 2018).

- Los centros educativos que participan quedan fidelizados y los docentes que cambian de destino logran implantarlo en sus nuevos centros, por lo que se está comportando como un evento multiplicador muy eficaz. Cada seminario docente está dejando varias líneas colaborativas abiertas y se ha puesto ya en funcionamiento un portal (http://red.climantica. org) para dar continuidad a los intercambios de experiencias y desarrollo colaborativo de iniciativas, estableciendo alianzas para presentar candidaturas de proyectos europeos e iberoamericanos.

- El equipo de educadores multidisciplinar está formado por exparticipantes que han participado de adolescentes seleccionados y existe una alta motivación en los escolares por poder llegar a formar parte de ese equipo juvenil de formación.

— Esta iniciativa ha merecido el máximo patrocinio de la UNESCO.

- Las metodologías colaborativas ya han fructificado en varios productos complejos de elevado impacto en las redes sociales como es el caso del vídeo Justicia Climática que ha alcanzado las 6.000 visualizaciones.

- El último musical creado, recientemente publicado en www.climantica.org, ya ha sido solicitado por comunidades educativas de la Red Climántica para ser representado en auditorios municipales demostrando su capacidad de sensibilización ciudadana.

\section{AGRADECIMIENTOS}

Este artículo pertenece al Proyecto Climántica, recomendado desde el año 2010 para su uso docente por el Alto Comisionado de las Naciones Unidas para el Cambio Climático. Agradecimiento 
especial a Pedro Losada, reportero fotográfico del proyecto y autor de las imágenes empleadas en este texto.
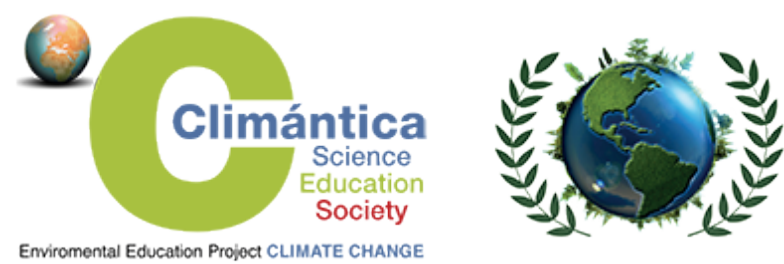

RECOMMENDED BY THE HIGH COMMISSIONER OF THE UNITED NATIONS ON CLIMATE CHANGE

\section{REFERENCIAS}

Abric, J. (1994). Prácticas sociales y representaciones. México: Ediciones Coyoacán.

Azevedo, J. y Marqués, M. (2017). Climate literacy: a systematic review and model integration. International Journal of Global Warming, 12(3-4), 414-430. DOI: https://doi.org/10.1504/ IJGW.2017.084789

Bathiany, S., Dakos, V., Scheffer, M. y Lenton, T. (2018). Climate models predict increasing temperature variability in poor countries. Science Advances, 4(5), 1-10. DOI: https://doi. org/10.1126/sciadv.aar5809

Cook, J. et al. (2016). Consensus on consensus: a synthesis of consensus estimates on humancaused global warming. Environmental Research Letters, 11(4), 1-7. DOI: https://doi. org/10.1088/1748-9326/11/4/048002

Dany, L., Urdapilleta, I. y Monaco, G. (2015). Free associations and social representations: some reflections on rank-frequency and importance-frequency methods. Quality \& Quantity, 49(2), 489-507. DOI: https://doi.org/10.1007/s11135-014-0005-z

Espejel, A. y Flores, A. (2015). Conocimiento y percepción del calentamiento global en jóvenes del bachillerato, Tlaxcala. Revista mexicana de ciencias agrícolas, 6(6), 1277-1290. DOI: https://doi.org/10.29312/remexca.v6i6.576

Feldman, L., Nisbet M., Leiserowitz A. y Maibach E. (2010). The climate change generation? Survey analysis of the perceptions and beliefs of young Americans. Yale Project on Climate Change and the George Mason University Center for Climate Change Communication.

García-Vinuesa, A. y Meira-Cartea P. Á. (2019). Caracterización de la investigación educativa sobre el cambio climático y los estudiantes de Educación Secundaria. Revista Mexicana de Investigación Educativa, 24(81), 507-535.

González-Gaudiano, É. J. (2007). Educación y cambio climático: un desafío inexorable. Trayectorias, $9(25), 33-44$.

González-Gaudiano, É. J. (2012). La representación social del cambio climático: una revisión internacional. Revista mexicana de investigación educativa, 17(55), 1035-1062.

IPCC (2018). Summary for Policymakers. In: Global Warming of $1.5^{\circ} \mathrm{C}$. An IPCC Special Report on the impacts of global warming of $1.5^{\circ} \mathrm{C}$ above pre-industrial levels and related global greenhouse gas emission pathways, in the context of strengthening the global response to the threat of climate change, sustainable development, and efforts to eradicate poverty. 
Monroe, M. C., Plate, R. R., Oxarart, A., Bowers, A. y Chaves, W. A. (2017). Identifying effective climate change education strategies: a systematic review of the research. Environmental Education Research, 25(6), 791-812. DOI: https://doi.org/10.1080/13504622.2017.1360842

Ramsing, R. y Sibthorp, J. (2008). The role of autonomy support in summer camp programs: preparing youth for productive behaviors. Journal of Park \& Recreation Administration, 26(2).

Salomon, E., Preston, J. L. y Tannenbaum, M. B. (2017). Climate change helplessness and the moralization of individual energy behavior. Journal of Experimental Psychology: Applied, 23(1), 15-28. DOI: https://doi.org/10.1037/xap0000105

Skanavis, C., y Kounani, A. (2018). Children communicating on climate change: the case of a summer camp at a Greek island. Handbook of Climate Change Communication, 3, 113-130. DOI: https://doi.org/10.1007/978-3-319-70479-1 7

Sóñora, F. (2009). Respuesta al cambio climático. El proyecto Climántica de Galicia. Cuadernos de Pedagogía, 392, 60-62

Sóñora, F. (2011). Innovación para la sociedad del cambio climático. Aula de Innovación Educativa, 206, 51-56.

Sóñora, F., y Alonso-Méndez, A. (2018). Ocean Under Global Change: From Science to School. International journal of environmental \& science education, 13(2), 97-112.

USGCRP (2009). Climate Literacy: The essential principles of climate science, A guide for individuals and communities. Disponible en http://cpo.noaa.gov/sites/cpo/Documents/pdf/Conocimiento Clim\%C3\%A1tico 8.5x11.pdf [Consulta: 5-09-2019].

UN General Assembly (2015). Transforming our world: the 2030 Agenda for Sustainable Development. Disponible en: https://www.refworld.org/docid/57b6e3e44.html [Consulta: 5-092019]. 